\title{
A comparative study of elective and emergency tracheostomy
}

\author{
A. Allam Choudhury ${ }^{1}$, Tuhin Sultana², Md. Abul Hasnat Joarder ${ }^{3}$, Kamrul Hassan Tarafder ${ }^{3}$,
}

\begin{abstract}
This is a cross sectional study done in I.C.U \& Dept. of otolaryngology - Head \& Neck Surgery, B.S.M.M.U, Dhaka and Dhaka Medical College Hospital during the period of $1^{\text {st }}$ March, 2003 to $30^{\text {th }}$ August, 2003. 60 cases of tracheostomies, were included in this study, among them 30 cases of elective tracheostomies and 30 cases of emergency tracheostomies. In this study mean age of elective tracheostomy was 40.46 years \& mean age of emergency tracheostomy was 50.50 years. Here Male was predominant both in elective (M:F= 6.5:1) and emergency tracheostomy (9:1). The common indications of elective tracheostomy were ICSOL (26.67\%) \& Head injury (26.67\%) where as commonest indication of emergency tracheostomy was laryngeal carcinoma (53.33\%). The frequency of complication for elective tracheostomy was $9.99 \%$ and emergency tracheostomy 33.35\%. Here complications were 3.33 times more common in cases of emergency tracheostomy then elective tracheostomy.
\end{abstract}

Key-words: Tracheostomy, elective and emergency.

\section{Introduction:}

The term tracheotomy is used to refer to the creation of a surgical opening into the trachea. Tracheostomy is used when a formal opening or stoma is made ${ }^{1}$. The early history of tracheostomy started with Galen \& Aretaeus. Galen approved the operation \& successfully opened the wind pipe of a goat . In 1934 E.W. Goodall was able to find only twenty eight successful cases of tracheostomy recorded up to the time of Bretonneau ${ }^{3}$. The chief indication were acute inflammations of the pharynx \& larynx and the removal of the foreign bodies ${ }^{3}$. Some authors credited Asclepiades of Bittynia (second century A.D) with honour of being the first to perform the operation ${ }^{2}$. The development of tracheostomy has been divided into five periods: the 'period of legend' dating from 2000 B.C. to A.D.

1546; the 'period of fear' from 1546 to 1833 during which the operation was performed only by a brave few, often at the risk of their reputations; the 'period of

1. Assistant Professor, Dept. of Otolaryngology- Head and Neck Surgery, BSMMU, Dhaka.

2. Assistant Professor, Dept of Clinical Pathology, BSMMU, Dhaka.

3. Professor, Dept. of Otolaryngology- Head and Neck Surgery, BSMMU, Dhaka

Address of Correspondence: Dr. A. Allam Chowdhury, Assistant Professor, Dept. of Otolaryngology- Head and Neck Surgery, BSMMU, Dhaka. drama' from 1833 to 1932 during which the procedure was generally performed only in emergency situation on acutely obstructed patient; the 'period of enthusiasm' from 1932 to 1965 during which the adage, 'if you think tracheostomy do it' became popular; and the 'period of rationalization' from 1965 to the present ${ }^{1}$.

Although the procedure of tracheostomy appears to have been performed in ancient times, it was considered hazardous and was then rarely performed until the early nineteenth century 4 .

In the past tracheostomy used to be reserved for severely ill patient with acute respiratory obstruction; gradually the indications for tracheostomy have been widened to include tracheobronchial toileting, intermittent positive pressure ventilation, protection against inhalation of foreign body and reduction of dead space $^{5}$.

Tracheostomy is thought as an important life saving procedure in many conditions \& has now become a well established procedure with more specific indications. It was found that tracheostomy is safer alternative to intubation when a prolonged artificial airway is required ${ }^{6}$.

Tracheostomy is a frequently performed procedure, historically has had a high rate of complications. It is one of the life saving procedure; here is very wise aphorism is that if a tracheostomy comes into ones 
mind then it is the time to do it . It has been found that in intensive care unit approximately $13 \%$ of patients will have a tracheostomy at any one time ${ }^{4}$.

In the recent years more and more airway problems are managed with either endotracheal intubation or percutaneous endoscopically guided tracheostomy ${ }^{4}$. But in our country percutaneous endoscopi- cally guided tracheostomy is not yet routinely practiced, conventional tracheostomy is practiced in vast majority of cases to manage airway problems. A conventional subhyoid tracheostomy is performed. Very few studies have been carried out comparing the elective and emergency tracheostomy. I have undertaken the study to see the common indications of these and to find out the pattern of complication in both type of tracheostomy to enrich the ideas for minimizing the complication.

\section{Patients \& methods:}

The study was done in I.C.U \& Department of Otolaryngology — Head \& Neck Surgery of Bangabandhu Sheikh Mujib Medical University Hospital, Dhaka. 60 cases of tracheostomies (30 cases of elective tracheostomies \& 30 cases of emergency tracheostomies) from $1^{\text {st }}$ March 2003 to $30^{\text {th }}$ August 2003 were included in this study.

\section{Methods:}

Place of study. BSMMU Dhaka.

Type of study- prospective study. Sample size- 60 (sixty). Duration of study - March 2003 to August 2003.

Data collection:

Interview of patient/ attendant Data collection sheet.

Inclusion criteria:

Elective tracheostomy-

(i) Patient already intubated in ICU assumed to require prolonged intubation period.

(ii) Patient with pre-operative planned tracheostomy. Emergency tracheostomy -

Patient with upper airway obstruction with stridor

Exclusion criteria

Patient below 2 years \& above 80 years.

\section{Results:}

The cases were consisting of two groups. The first group was composed of 30 patients of elective tracheostomy and second group was composed of
30 patients of emergency tracheostomy. Majority (22 cases) of elective tracheostomy patients were selected from I.C.U, in which cases patients were intubated at least 24 hours before tracheostomy. So the indications of elective tracheostomy may vary from other studies done in home and abroad.

In this study indications and complications of both elective and emergency tracheostomy and their morbidity were studied. In this study lowest and highest age of the patients at presentation was 3 years to 76 years. Mean age for elective tracheostomy was 40.46 years and mean age for emergency tracheostomy was 50 .

\section{Age Distribution}

Table-I

\begin{tabular}{lcc}
\hline $\begin{array}{l}\text { Age group } \\
\text { (years) }\end{array}$ & \multicolumn{2}{c}{ Number of Patients (\%) } \\
\cline { 2 - 3 } & $\begin{array}{c}\text { Elective } \\
\text { tracheostomy } \\
(\mathrm{N}=30)\end{array}$ & $\begin{array}{c}\text { Emergency } \\
\text { tracheostomy } \\
(\mathrm{N}=30)\end{array}$ \\
\hline $00-10$ & $2(6.67 \%)$ & $2(6.67 \%)$ \\
$11-20$ & $2(6.67 \%)$ & $2(6.67 \%)$ \\
$21-30$ & $4(13.33 \%)$ & $3(10 \%)$ \\
$31-40$ & $7(23.33 \%)$ & $3(10 \%)$ \\
$41-50$ & $9(33.33 \%)$ & $4(13.33 \%)$ \\
$51-60$ & $4(13.33 \%)$ & $10(33.33 \%)$ \\
$61-70$ & $1(3.33 \%)$ & $5(16.67 \%)$ \\
$71-80$ & $1(3.33 \%)$ & $1(3.33 \%)$ \\
\hline
\end{tabular}

Table-II

Sex distribution

\begin{tabular}{lcccc}
\hline Sex & \multicolumn{2}{c}{$\begin{array}{c}\text { Elective } \\
\text { tracheostomy } \\
(\mathrm{n}-30)\end{array}$} & \multicolumn{2}{c}{$\begin{array}{c}\text { Emergency } \\
\text { tracheostomy } \\
(\mathrm{n}-30)\end{array}$} \\
& Number & Percent & Number & Percent \\
\hline Male & 26 & $86.67 \%$ & 27 & $90 \%$ \\
Female & 4 & $13.33 \%$ & 3 & $10 \%$ \\
\hline
\end{tabular}

Table-III

Socio economic conditions of the patients

\begin{tabular}{lcc}
\hline Class & $\begin{array}{c}\text { Elective } \\
\text { tracheostomy } \\
(\mathrm{n}-30)\end{array}$ & $\begin{array}{c}\text { Emergency } \\
\text { tracheostomy } \\
(\mathrm{n}-30)\end{array}$ \\
\hline Low & 10 & 18 \\
Middle & 11 & 8 \\
High & 9 & 4 \\
\hline
\end{tabular}


Table-IV

Indications elective tracheostomy

\begin{tabular}{lcc}
\hline Diagnosis & \multicolumn{2}{c}{ Elective tracheostomy } \\
\cline { 2 - 3 } & Number & Percent \\
\hline 1. Carcinoma Larynx & 4 & $13.33 \%$ \\
2. Carcinoma of hypopharynx & 2 & $6.67 \%$ \\
3. Carcinoma of base of the tongue & 1 & $3.33 \%$ \\
4. Carcinoma of mandible & 1 & $3.33 \%$ \\
5. Guillain- Barre syndrome & 3 & $10 \%$ \\
6. Cerebrovascular accidents & 3 & $10 \%$ \\
7. Head injury with history of R.T.A. & 8 & $26.67 \%$ \\
8. Postoperative case of I.C. S.O.L. & 8 & $26.67 \%$ \\
\hline
\end{tabular}

Table-V

Indications of emergency tracheostomy

\begin{tabular}{lcc}
\hline Diagnosis & \multicolumn{2}{c}{$\begin{array}{c}\text { Emergency tracheostomy } \\
(\mathrm{n}=30)\end{array}$} \\
& Number & Percent \\
\hline 1. Carcinoma Larynx & 16 & $53.33 \%$ \\
2. Carcinoma of hypopharynx & 4 & $13.33 \%$ \\
3. Carcinoma of thyroid gland & 2 & $6.67 \%$ \\
4. Multiple papilloma of larynx & 2 & $6.67 \%$ \\
5. Cerebrovascular accidents & 2 & $6.67 \%$ \\
6. Head injury with history of R.T.A. & 2 & $6.67 \%$ \\
7. Postoperative case of I.C. S.O.L. & 1 & $3.33 \%$ \\
\hline
\end{tabular}

Table-VI

Complications ofxtracheostomy

\begin{tabular}{lcc}
\hline Complications & $\begin{array}{c}\text { Elective tracheostomy } \\
(\mathrm{n}=30)\end{array}$ \\
& Number & Percent \\
\hline Surgical emphysema & 1 & $3.33 \%$ \\
Haemorrhage & 1 & $3.33 \%$ \\
Wound infection & 1 & $3.33 \%$ \\
\hline Total & & $9.99 \%$ \\
\hline
\end{tabular}

Table-VII

Complications of emergency tracheostomy

\begin{tabular}{lcc}
\hline Complications & $\begin{array}{c}\text { Emergency tracheostomy } \\
(\mathrm{n}=30) \\
\text { Number }\end{array}$ & $\begin{array}{l}\text { Percent } \\
\text { Surgical emphysema }\end{array}$ \\
Haemorrhage & 2 & $10 \%$ \\
Tube blockage & 1 & $6.67 \%$ \\
Tube displacement & 1 & $3.33 \%$ \\
Wound infection & 1 & $3.33 \%$ \\
Stomal recurrence & 1 & $3.33 \%$ \\
Tracheocutane ous fistula & 1 & $3.33 \%$ \\
Total & & $33.33 \%$ \\
\hline
\end{tabular}

\section{Discussion:}

Both elective and emergency tracheostomy are one of the common surgical procedure but not always without complications ${ }^{7}$. In this study 60 cases of tracheostomies ( 30 cases of elective and 30 cases of emergency tracheostomies) were studied prospectively to see the indications of elective and emergency tracheostomy and their complications and to see whether there is any significant difference between two types of tracheostomy. The values were compared to some other published report from country and abroad.

In this study mean age of elective tracheostomy was 40.46 years and mean age of emergency tracheostomy was 50.50 years. In one study in Dhaka Medical Collage Hospital mean age of cases was 46.54 years $^{10}$ The age of those with malignant condition is significantly higher than those of non malignant condition both in elective and emergency tracheostomy. In a previous study highest frequency of tracheostomy for malignant condition ${ }^{11}$, the age group was 45-60 years, in this study it was age group of $40-70$ years.

Here the male was predominant both in elective (M:F = 6.5: 1) \& emergency tracheostomy (9:1). This findings has similar with previous two studies which were done in Dhaka Medical College Hospial ${ }^{10 \cdot 11}$.

In elective tracheostomy patient were from all classes but in case of emergency tracheostomy majority people were from poor socio economic conditions ${ }^{1011}$. Tracheostomy for malignant condition was significantly more common in those with lower levels of education. It is observed that in this group of patients presented in a more advanced stages of disease. There is similarity with previous two studies ${ }^{10 \cdot 11}$.

The common indications of elective tracheostomy were intracranial space occupying lesion (ICSOL) (26.67\%) and Head injury (26.67\%); other indications were preoperative tracheostomy for carcinoma mandible,Guillain-Barre Syndrome, Cerebrovascular accidents etc.

The commonest indications for emergency tracheostomy was laryngeal carcinoma (53.33\%). It was followed by advanced hypopharyngeal carcinoma (13.33\%) and. In another study these indications were found in $47 \%$ \& $12 \%$ cases respectively ${ }^{11}$.

In this study of complicaitons for elective tracheostory was $9.99 \%$ \& emergency tracheostomy was $33.35 \%$. 
In a study in Dhaka Medical College Hospital rate of complications was $39.05 \%{ }^{10}$. Most restrospective studies have assessed the overall incidence of complications and these ranged from $5 \%$ to $40 \% 12$. The complication in this study within the range of this study. The rate of complications was similar to previous studies carried in home \& aborad 11,13,14

Mortality due to complications of emergency tracheostomy was $3.33 \%$. No mortality was in elective tracheostomy. So over all mortality rate is $1.67 \%$. The mortality was due to tube displacement as occured due to huge emphysema in neck. In a study in Dhaka Medical College Hospital fatality due to complications of tracheostomy was $1.78 \%{ }^{10}$. The fatalities were due to tube displacement and tube blockage $^{10}$. In review of literatures the death rate was found to range from $0.50 \%$ to $1.60 \%$ and most often it was cause by haemorrhage or tube displacment ${ }^{1}$.

In this study no death was caused by haemorrhage both from elective or emergency tracheotomy. In some other studies death rate were found to be $1.00 \%$, $0.49 \%$ and $1.78 \%,{ }^{11^{\prime}} 15^{\prime} 16$ '

The complications were more common in cases of emergency tracheostomy (33.35\%) than in cases of elective tracheotomy (9.99\%); the difference is statistically significant. One study Dhaka Medical college Hospitl showed complications were more common in cases of emergeny tracheotomy (43.26\%) than in cases of routine ones $(17.8 \%)^{10}$. In another previous studies on elective tracheotomy showed the rate of complications are $8.94 \%^{7}$ and $19.64 \%^{20}$. respectivly Review of previous literatures showed that comlications for surgical tracheostomies were $41 \%$, $51 \%$ and $58.62 \%^{11}{ }^{13}{ }^{14}$. Here complications were 3.33 times more common in cases of emergency tracheostomy than electrive tracheotomy. In a study Dhaka Medical College Hospital complication were 2.42 times more common in cases of emergency tracheotomy then routine ones ${ }^{10}$. It is recognized that emergency tracheotomy carries two to five fold increase in the incidence of complication over an elective procedure. The rate of complications did not show association with the nature of pathological conditions necessitating tracheotomy.

In this study surgical emphysema was commonest complications both for elective (3.33\%) \& emergency tracheotomy (10\%) In a previous study surgical emphysema was the commonest complication $(9.47 \%)^{10}$. Subcutaneous emphysema can be alarming, but is seldom fatal. It is mostly confined to the neck but can extend to the face and chest wall. It usually presents within the first day and is self-limiting by the seventh day, unless the precipitating factors persists. To tight closure of the skin or subcutaneous tissue, too large incision in the trachea, improperly fitting tracheotomy tube and excessive coughing are the causative factors ${ }^{1}$. The risk of tracheotomy tube displacement is increased in cases of marked surgical emphysema due to increase in neck swelling.

The second commonest complication was hemorrhage both for elective tracheotomy (3.33\%) emergency tracheotomy (6.67\%). In a previous study second common complication was hemorrhage $(5.33 \%)^{10}$. In other studies it was found to be $3.7 \%$ and $5.0 \%$ Haemorrhage is most commonly arising from anterior jugular veins \& thyroid gland ${ }^{1}$.

Tube blockage was found in $3.33 \%$ in cases of emergency tracheotomy but there is no tube- blockage in elective tracheotomy. In some other studies it was found to be in $2.7 \%, 2 \%$ and $3.5 \%$ cases respectively $1,11,10$ tracheotomy alters the basic physiology of the inspired air from filtered, warm and humidified to dry cold air comming into direct contact with the trachea. This alterations dry up the tracheal and pulmonary secretions and interferes with ciliary capacity to move the mucous blankets, and thus causes production of thick, tenacious mucuous scabs \& crusts. If the situation is not controlled the scab will increase in size with the result that they are difficult or impossible to cough out or even removed by suction ${ }^{1}$.

Tube displacement was found $3.33 \%$ cases. In a previous study tube displacement was found in $2.96 \%{ }^{10}$ cases, which was found in $1.5 \%$ ' and $4 \%{ }^{11}$ casos in other studies ${ }^{1,11}$ Length of the tube and thickness of the neck are clearly the most important factors; postoperative oedema, haematoma and emphysema will cause a broadening of the distance between the skin surface and the anterior wall of the trachea ${ }^{1}$. Overweight patient or patient with full neck or when the patient coughs excessively or moves the head tube can easily slips out of the trachea and into the interstitial tissues of the neck ${ }^{18}$.

Wound infection was found in $3.33 \%$ cases both in elective and emergency tracheostomy. In a previous study it was $2.96 \%{ }^{10}$ of cases. In a study bacterial contamination in the neck wound was found in 35\% cases in open tracheostomy ${ }^{19}$. Fortunately infection 
in the neck in tracheostomy is local, indolent and produces local cellulitis with some granulation tissues. Antibiotics are seldom necessary as the wound is open and drainage is adequate ${ }^{1}$.

Stomal recurrence found in $2.5 \%$ cases, excessive granulation tissue formation was found in $2.5 \%$ cases, tracheocutaneous fistula was found $2.5 \%$ cases, cardiac arrest was found in $2.5 \%$ cases, decanulation problem was found in $2.5 \%$ cases. These all complications were found in emergency tracheostomy. There was no subglottic stenosis was found in cases. Tracheostomal stenosis is a distressing complications ${ }^{20}$. Stenosis occurs at three levels the stoma, the cuff site or the tip of the tube. The majority of the cases result from the pressure of the inflatable cuff on the trachea. Most nonmalignant upper tracheal stenosis are caused by prolonged endotracheal intubation or tracheostomy ${ }^{21}$. According to another author some tracheal narrowing is demonstrated in more often seen near the site of stoma ${ }^{22}$. Functional impairment is rare unless trachea has been narrowed by more than $50 \%$ as measured on biplane radiographs ${ }^{1}$.

\section{References:}

1. Bradley P.J. Management of obstructive airway \& tracheostomy. In: Scott Brown's Otolaryngology. Reed educational \& professional publishing Ltd. Great Britain. 1997 (6 $6^{\text {th }}$ edition); Page: 5/7/1-20.

2. Weir N. The early history of tracheostomy; The middle age \& renaissance. In; OtolaryngologyAn Illustrated History. Butterworth \& Co. Ltd.; University press Cambridge, Great Britain 1990; Page 24-38.

3. Goodall, E.W. (1934) The story of tracheostomy. The British Journal of Children's diseases, 31, (I) 167-176 (ii) 253-272.

4. Watkinson JC, Gaze MN, Wilson J.A. Treatment options: the principles of surgery. In Stell and Maran's Head and Meek Surgery. Butter worthHeinemann. Reed educational \& professional publishing Ltd. Oxford 2000. Page 49-65.

5. Me Clelland RMA, Complications of trachesotomy. British Medical Journal. 1965; 2: 567-9.

6. Juvekar Mr., Juvekar R.V., comparative study of endotracheal intubation and tracheostomy in emergencies: A Review of 70 cases. BHJ 1999; P-486-490.

7. Upadhyay A. Maurer J. Tiszenkel H, Rosengart $\mathrm{T}$. Elective bedside tracheostomy in intensive care unit. Journal of American College of Surgery 1996; 110 (2); 480-5.

8. Watkinson JC, Gaze MN, Wilson JA. Tracheostomy. In: Stell \& Maran's Head and neck surgery. Butterworth Heinemann. Reed educational and Professional publishing Ltd. Oxford, 2000, Page 163-168.

9. Taicher H. Vivol N. Peleg M. Ardekian L. 0 Changing indications for tracheostomy in maxillofacial trauma, Journal of oral \& maxillofacial surgery 1996; 54(31); 292-6.

10. Rahman S.H., Ahmed K, Khan A.F.M, Ahmed S.U, Hanif M.A., Haroon A.A. Islam M.A. study of tracheostomy in Dhaka medical Collage hospital; Bangladesh Journal of Otorhinolaryngolpgy 2001; 7(2): 34-40.

11. Ahmed K, Rahinan M.A., Rahman S.H, Complications of tracheostomy. Bangladesh Journal of otorhinolaryngology 1998 4)1): 3-6.

12. Miller J.D, Knapp J.P. Complications of tracheostomy in neurological patients. Surgery and neurology, 1984:22: 186-8.

13. Friedman Y. Fildes, Mizock B, Samuel J, Patel S. Appavu S. Roberts R. Comparison of percutaneous and surgical tracheostomies. Chest 1996; 100 (2): 480-5.

14. Graham T.S. Mulloy R.H. Sutherland F.R; Rose $\mathrm{S}$. Percutaneous versus open tracheostomy; a retrospective cohort outcome study. Journal of trauma: 1996; 41(2): 245-50.

15. Wease GL. Frikker M. Villalba M. Glover J. Bedside tracheostomy in intensive care unit. Archives of surgery. 1996; 131 (5) : 552-5.

16. Shinkwin C.A. Gibbin K.P. Tracheostomy in children. Journal of Royal society of medicine. 1996: 89 (4): 188-92.

17. Reilly. H. and Sasaki C.T. (1993) Tracheostomy Complications. In : complications in Head and Neck Surgury, edited by Y.P. Krespi and R.H. Ossoff. Philadelphia W.B. Saunders P.P. 257274. 
18. Seay S.J. Gay S.L. Problems in tracheostomy patients care: recognizing a patient with displaced tracheostomy tube. Otorhinolaryngology Head \& Neck nursing. 1997; 15 (2): 10-11.

19. Westphal K, Byhahn C, Rinne T, Wilke HJ, / Wimmer-Greinecker, Lischke V. Tracheostomy in cardiosurgical patient. Annals of Thoracic Surgery. 1999;68 (2) : 486-92.
20. Wax MK. Touma BJ, Ramadan HH, Management of tracheostomal stenosis. Larygoscope. 1999; 109 (9)1397-401.

21. Yamada S, Kikuchi K, Kosaka A, Inoue $\mathrm{H}$, Is Umemura S.Surgical management of idiopathic tracheal stenosis. Japan Journal of Thoracic and Cardoverscular Surgery. 1999; 47 (7): 335-8.

22. Lulenski G.C. Longterm tracheal dimension after flap tracheostomy. Archives of Otolaryngology.1981; 107: 114-9. 